\title{
Computer Controlled Induced Hypothermia in Victims of Out-of-Hospital Cardiac Arrest
}

\author{
RJ Leor-Librach, S Gmach-Fluk, I Jasmawie, V Nachliely, O Ezra \\ Heart Institute, Laniado Hospital, Sanz medical Center, Netanya, Israel
}

\begin{abstract}
Out-of-hospital cardiac arrest is a condition with high mortality and devastating morbidity. Until most recently there was no specific therapy apart from strict monitoring and supportive care. Results from animal studies and a few recent clinical trials suggest a beneficial effect of induced mild hypothermia on the neurologic outcome. We treated 22 successive patients with 24 hours of induced hypothermia to $34.5^{\circ} \mathrm{C}$ and compared their outcome to our last 16 patients who were hospitalized before we started the project.

Patients were connected to a microprocessor-based heat pump that supplied warmed or cooled water to the ThermoWrap ${ }^{\mathrm{TM}}$ garment worn by the patient.

The cooling system we used lowered patients' temperature to a mean of $34.5 \pm 0.7^{\circ} \mathrm{C}$ at a mean time of $6.2 \pm 2.5$ hours. $59 \%$ of the hypothermia patients were discharged conscious as compared to $25 \%$ of the patients who were treated conservatively $p<0.03$. The mortality rate was $29 \%$ in the hypothermia group and $37 \%$ in the conservative care group $P=N S$.

We conclude that the computerized cooling system we used, adequately lowered and stabilized our patients' temperature on the desired target level. Induced mild hypothermia is beneficial in victims of out-of-hospital cardiac arrest. The issue of controlled cooling of patients is complex and should be further investigated.
\end{abstract}

\section{Introduction}

Patients who remain unconscious after resuscitation from cardiac arrest have a poor prognosis. It is believed that part of the anoxic brain injury occurs after the return of spontaneous circulation [1]. Until most recently there was no specific therapy apart from strict monitoring and supportive care. Results from animal studies and several recent clinical trials suggest a beneficial effect of induced mild hypothermia on the neurologic outcome [2,3]. This study was initiated in order to assess the feasibility, complications and efficacy in our patients with out-ofhospital cardiac arrest.

\section{Methods}

All patients who were resuscitated after out-ofhospital cardiac arrest, and arrived in coma, were admitted directly to the intensive coronary care unit.

They were ventilated and paralyzed with pancuronium. Patients were connected to the Allon 2001 system which is a microprocessor-based heat pump that supplies warmed or cooled water to the ThermoWrap ${ }^{\mathrm{TM}}$ garment worn by the patient. Water temperature is determined as a function of the actual patient core and surface temperatures and physician set point $\left(30^{\circ} \mathrm{C}-40^{\circ} \mathrm{C}\right)$ by means of a proprietary and unique algorithm developed by MTRE Advanced Technologies Ltd., Israel. Core temperature was sampled by a termistor placed in the esophagus.

The outcome of our hypothermia patients was compared to the outcome of our last 16 patients who were hospitalized before we started the project by the Fisher exact test for 2 x 2 tables.

\section{Results}

The cooling system we used lowered patients' temperature to a mean of $34.5 \pm 0.7^{\circ} \mathrm{C}$ at a mean time of $6.2 \pm 2.5$ hours. Figure 1 shows a representative cooling curve.

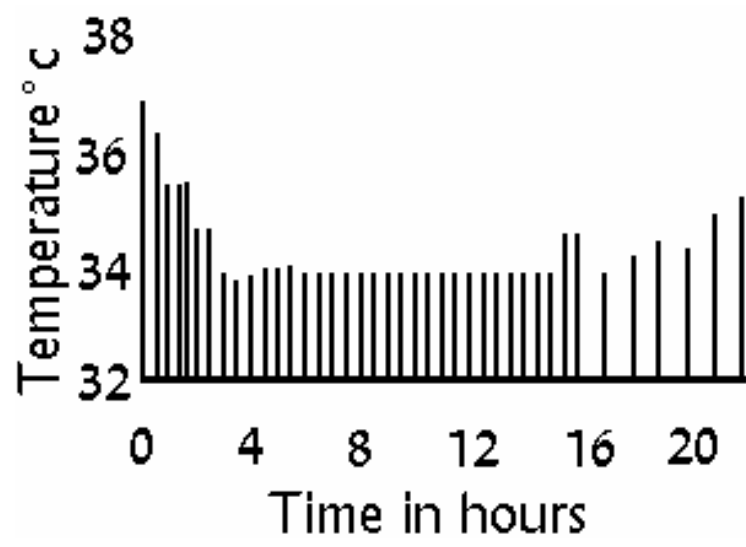

Figure 1. A representative cooling curve from one of our patients. 
$59 \%$ of the hypothermia patients were discharged conscious as compared to $25 \%$ of the patients who were treated conservatively $\mathrm{P}<0.03$. The mortality rate was $29 \%$ in the hypothermia group and $37 \%$ in the conservative care group $\mathrm{P}=\mathrm{NS}$.

\section{Discussion}

Evidence suggests that the neurologic injury after outof-hospital cardiac arrest continues after reperfusion [1] Possible mechanisms include the formation of oxygen free radicals from metabolites of arachidonic acid which injure the cell membrane [4] and eventually cause cerebral edema and raised intracranial pressure [5]. The mechanism by which hypothermia works is unclear. It decreases oxygen demand of cerebral tissues and probably decreases the activity of enzymes involved in formation of the oxygen free radicals. Hypothermia is known to decrease cerebral edema [6].

Heat formation and transfer within the body compartments is a complex process [7]. Various methods of body cooling have been employed. The most popularly used is external cooling which is slower but seems safer [2-3]. Peritoneal cooling is rapid but is not generally used. Extracorporeal blood cooling and intravenous heat exchangers [8] are rapid but are invasive and involve logistic difficulties.

We used a computer-controlled external cooling system which was able to cool our comatose patients after cardiac arrest to $34.5^{\circ} \mathrm{C}$ at an average interval of 6 hours. The outcome of our patients significantly improved to the same extent as in the other studies [2-3].

We conclude that the computerized cooling system we have used, adequately lowered and stabilized our patients' temperature to the desired target level. Induced mild hypothermia is beneficial in victims of out of hospital cardiac arrest. The issue of controlled cooling of patients is complex and interesting and should be further investigated.

\section{References}

[1] Vaagenes P, Ginsberg M, Ebmeyer U, et al. Cerebral resuscitation from cardiac arrest: Pathophysiological mechanisms. Crit Care med 1996; 24: S57-S68.

[2] Bernard SA, Gray TW, Buist MD, Jones BM, Silvester W, Gutteridge G, Smith K. Treatment of comatose survivors of out-of-hospital cardiac arrest with induced hypothermia. N Engl J Med 2002; 346: 557-563.

[3] The hypothermia after cardiac arrest study group. Mild therapeutic hypothermia to improve the neurologic outcome after cadiac arrest. N Engl J Med 2002; 346: 549556.

[6] Shiozaki TS, Sugimoto H, Taneda M et al. Effect of mild hypothermia on uncontrollable intracranial hypertension after severe head injury. J Neurosurg 1993; 79: 363-367.

[7] Sessler DI. Perioperative heat balance. Anesthesiology 2000; 92: 578-596.

[8] Georgiadis D, Schwarz S, Aschoff A, Schwab S. Hemicraniectomy and moderate hypothermia in patients with severe ischemic stroke. Stroke 2002; 33: 1584-1588.

\section{Acknowledgements}

We would like to thank Mrs. Shulamit Dembs for proof reading the article.

Address for correspondence.

Ron Joseph Leor-Librach M.D. Ph.D.,

The Heart Institute, Lanido Hospital, Sanz Medical Center, P.O.Box 744, Netanya, 42107, ISRAEL.

rellb@post.tau.ac.il 